\section{Use of a self-expandable metallic stent for large bile leakage following orthotopic liver transplant}
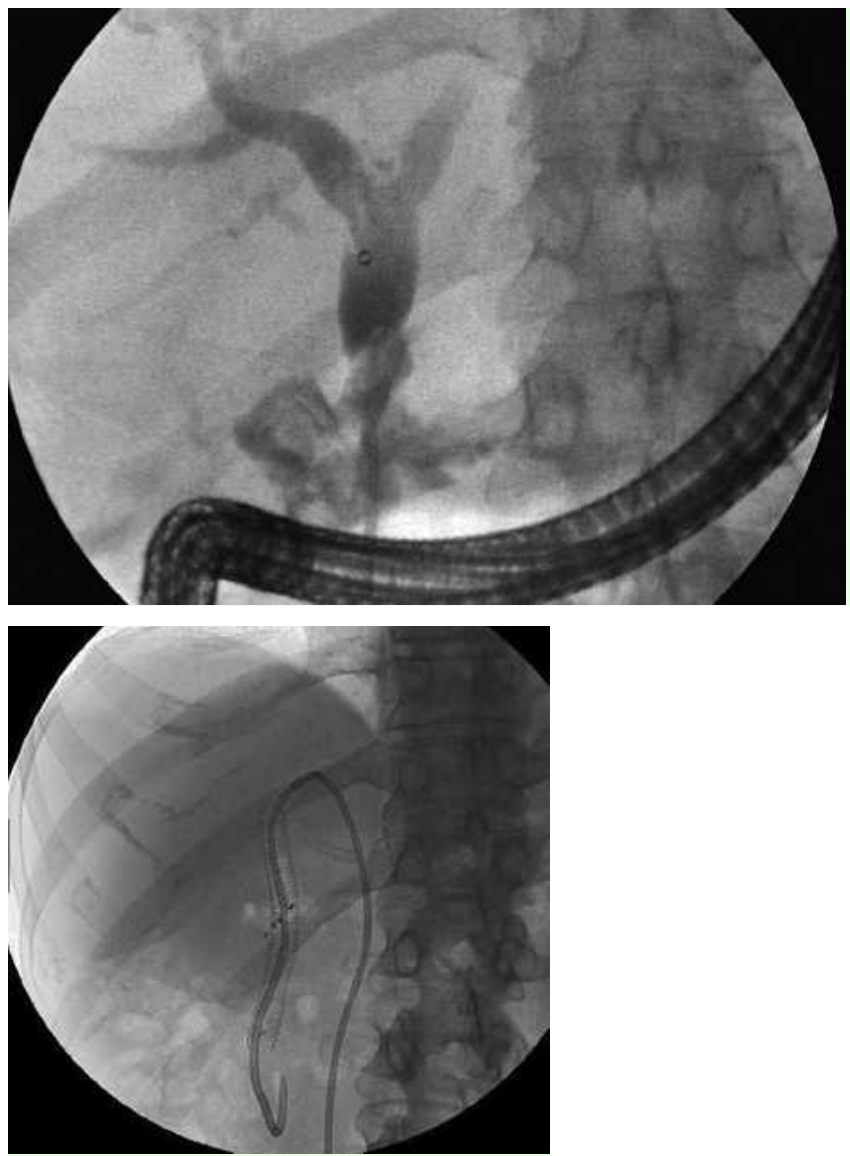

Fig. 2 A self expandable metallic stent is placed.

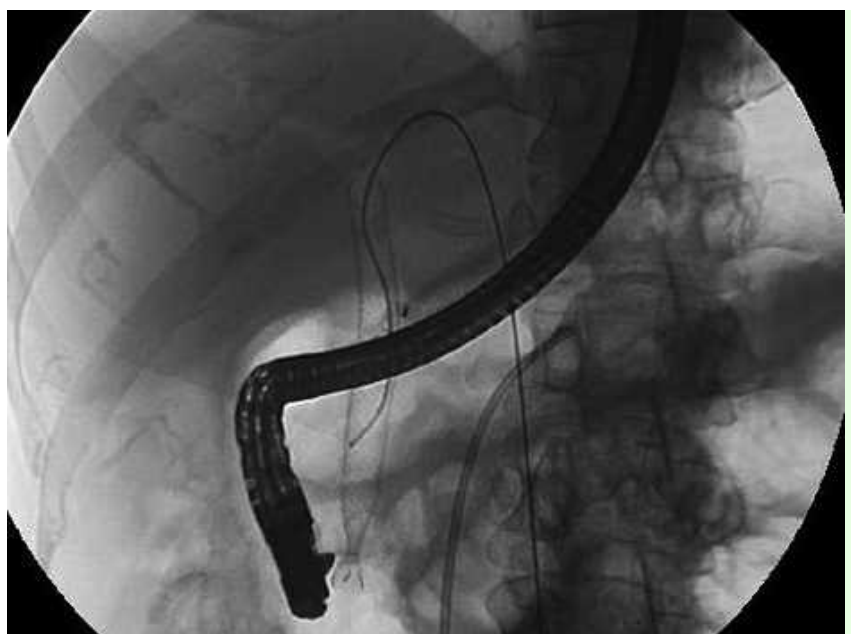

Fig. 1 A large bile leak is visualized at endoscopic retrograde cholangiopancreatography (ERCP).

Fig. 3 The metallic stent is removed with a snare.
Biliary leaks are the most frequent complication after both liver transplantation and major liver surgery [ $1-3]$. In the current literature, there are very few reports on the use of a metallic stent for large bile leakage, especially after liver transplantation $[4,5]$.

We report a case of substantial biliary leakage following orthotopic liver transplantation, that was treated with a selfexpanding metallic stent. Further studies are necessary to confirm the use of such metallic stents as a valid and safe treatment for bile leakage following liver transplant.

In 2007, a 61-year-old man underwent orthotopic liver transplantation with a choledocho-choledocho anastomosis for cirrhosis related to hepatitis $B$ and hepatitis D virus (HBV and HDV).

The patient was admitted to our facility 1 month later because of fever and computed tomography (CT) evidence of a large perihepatic collection $(7.8 \times 3.5 \mathrm{~mm})$. At admission, laboratory data were: aspartate aminotransferase (AST) $288 \mathrm{U} / \mathrm{L}$ (normal range $15-37 \mathrm{U} / \mathrm{L})$, alanine aminotransferase (ALT) 400U/L (normal 30$65 \mathrm{U} / \mathrm{L}$ ), total bilirubin $1.97 \mathrm{mg} / \mathrm{dL}$ (normal $0.10-1.10 \mathrm{mg} / \mathrm{dL}$ ), direct bilirubin $0.94 \mathrm{mg} / \mathrm{dL}$ (normal $0-0.30 \mathrm{mg} / \mathrm{dL}$ ), alkaline phosphatase $165 \mathrm{U} / \mathrm{L}$ (normal range $40-134 \mathrm{U} / \mathrm{L})$, and gamma glutamyltransferase (GGT) 212U/L (5-85U/L).

With the patient under general anesthesia, a percutaneous $10-\mathrm{Fr}$ abdominal drainage was placed using ultrasound guidance, and was connected to an external biliary catheter. At the same time, endoscopic retrograde cholangiopancreatography (ERCP) was done to rule out possible biliary leakage. The choledochus was cannulated and a large bile leak was observed ( $\bullet$ Fig. 1). Because of the size of the leak, a self expandable metallic stent $(10 \mathrm{~cm} \times 1 \mathrm{~cm}$, Wallstent; Boston Scientific, Massachusetts, USA) was placed across the leak ( $\bullet$ Fig. 2). Finally, a 10-Fr Ring external-internal biliary catheter (Boston Scientific) was also inserted so that the bile output could be monitored. The patient was discharged 5 days later, in good general condition, asymptomatic and without fever. The internal-external biliary catheter and the biliary stent were removed 2 months later, and there was complete resolution of the fistula ( 1 Fig. 3 and 4). After 6 months, the patient remained in a good general condition, with no evidence of recurrence of the biliary leak. 


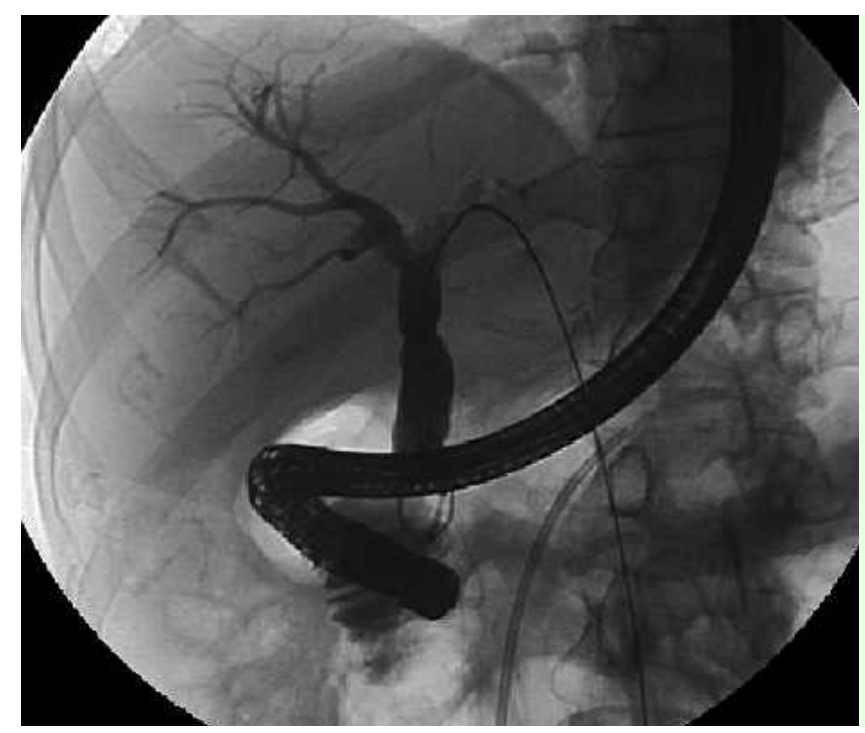

Fig. 4 Normal cholangiographic findings after stent removal.

Endoscopy_UCTN_Code_TTT_1AR_2AG

M. Di Pisa, M. Traina, R. Miraglia, R. Volpes, S. Gruttadauria, A. Luca, B. Gridelli

IsMeTT, UPMC, Palermo, Italy
Bibliography

DOI 10.1055/s-2008-1077695

Endoscopy 2009; 41: E4-E5

(c) Georg Thieme Verlag KG Stuttgart · New York . ISSN 0013-726X

Corresponding author

\section{Di Pisa, MD}

Department of Gastroenterology

IsMeTT, UPMC

Via Tricomi 1

Palermo

Italy 90100

Fax: +39-91-2192400

mdipisa@ismett.edu 